\title{
MARÍA JESÚS RUBIERA Y SUS ESTUDIOS SOBRE LITERATURA ÁRABE
}

\author{
Pedro MARTÍNEZ MONTÁVEZ \\ Universidad Autónoma de Madrid
}

Cuando el estudio y el análisis de la obra del arabismo español plenamente contemporáneo se hagan como se debe: es decir, con condición sosegada, extensa, documentada y reflexiva, y no de manera arrebatada, reductora, sectorista y visceral -como, a mi parecer, suele ocurrir- quedarán entonces pertinentemente establecidos no sólo los rasgos fundamentales de carácter individual sino también los generacionales y de grupo. Se trata de una tarea que, como tantas otras, requiere ante todo una perspectiva histórica más alejada y una visión mental más correcta: es decir, tiempo y objetividad. No resultan, por consiguiente, dos imposibles, aunque tampoco constituyan una empresa fácil. Conviene que empecemos a pensar en todo esto. Se verá entonces también en qué grado y medida la obra de ese arabismo forma parte -o no- de la cultura española también plenamente contemporánea, refleja y se hace eco -o no, vuelvo a repetir- de su específico proceso de conformación y manifestación. La cuestión, en consecuencia, no tiene nada de baladí, y sí constituye un desafío intelectual, un acicate, de primer rango.

Digo todo esto, de entrada, con un propósito recto, claro e independiente. La lectura de la producción escrita de la profesora Marfa Jesús Rubiera Mata, y en concreto los estudios que ha dedicado hasta ahora a la literatura árabe, nos permite ante todo, obviamente, conocer, caracterizar y distinguir su obra personal ${ }^{1}$, pero refleja también

${ }^{1}$ Como se comprenderá, no me propongo en esta breve contribución hacer 
seguramente $-y$ en algunos aspectos, quizá, de forma ejemplar o especialmente traslúcida- los que son rasgos ampliamente comunes a los arabistas de su generación: la "generación de los sesentas", posiblemente; características al menos parcialmente compartidas. Voy a mencionar, estrictamente, tres, que considero particularmente importantes $y$ significativas: el propósito consciente de renovación de una tradición, una mayor exigencia metodológica docente, y una aptitud menos rígida ante la posible presencia y actuación de elementos de empatfa, que pueden contribuir a superar un cientificismo exagerado y bastante anacrónico. Se trata de rasgos y características presentes y actuantes también seguramente en la generación anterior, la de los "cincuentas" -es decir, la mia ${ }^{2}$ - pero que en ésta siguen un comportamiento individual preferentemente, y que se hace algo más colectivo en aquélla. Suscito aqui simplemente la cuestión.

El simple repaso de la bibliografía general de la profesora Rubiera Mata certifica que la literatura árabe medieval constituye desde el principio una de las dedicaciones más importantes, enjundiosas y permanentes, en su tarea investigadora, traductora, y de acertada difusión cultural y de divulgación pública. Aprovecho para decir que a mí no me parece desplazado ni erróneo calificar también a esa literatura de clásica, puesto que no es el dato estrictamente cronológico el único que la caracteriza y acuña, genéricamente, y la flexibilidad semántica del término "clásico" lo permite de sobra.

Conviene recordar y tener presente desde un principio que, dentro del extensísimo y polifacético terreno de la literatura árabe medieval -en

una presentación descriptiva y temática, con reiteración enumerativa de títulos, de la obra de la profesora Rubiera Mata. Basta leer su abundante bibliografia, que se incluye en este volumen, para documentarse al respecto. Advierto asimismo que mi aproximación al tema es eminentemente global, al incluirse otras varias, tambiên sobre literatura árabe, de contenido más monográfico y particular.

2 Hablo de generaciones como debe hablarse: con flexibilidad. Las denominaciones que empleo hacen referencia, naturalmente, a los años de formación universitaria y de iniciación en la investigación. 
última instancia inabarcable en su totalidad- el objeto casi exclusivo de atención e investigación directas del arabismo español universitario ha sido la literatura andalus o hispanoárabe ${ }^{3}$. Como todas las opciones -y de ello no quedan excluidas, obviamente, la cientifica- esto implica sus pros y sus contras, sus ventajas y sus inconvenientes. Está absolutamente justificado a mi entender, no obstante, que tal preferencia se produzca, por la simple e imponente razón de que constituye una parte singular y enjundiosa de nuestra propia cultura nacional, en su globalidad y en sus correspondientes modalidades o variantes. Resulta, pues, un signo de lógica y de coherencia y no tiene nada de irregular o sorprendente. Distinto es, naturalmente, que trate de mantenerse en términos de absolutismo y de exclusión de otras opciones lícitas y caracterizadas, lo que resulta totalmente reprochable y rechazable por lo que tiene, ante todo, de anticientifico. El riesgo y el error, graves, no radican en el reduccionismo temático, sino en el reduccionismo intelectual y conceptual. Voy a adelantar otro rasgo caracterizador de la obra de la profesora Rubiera Mata: está centrada consciente y claramente en el estudio de la literatura hispanoárabe, pero también está exenta de las torpes e injustificadas asechanzas de cualquier tipo de reduccionismo.

De la misma manera que se ha venido dando desde antiguo una preferencia de objeto, se ha venido dando también una preferencia de método. El estudio universitario de la literatura ha estado tradicional y abusivamente inscrito en el área de la filología, y se ha hecho muy mayoritariamente a partir de planteamientos, objetivos y gustos filologicos. Dejando ahora al margen otras pertinentes valoraciones y caracterizaciones, lo que resulta indudable es que la filología es una disciplina de naturaleza histórica también, y el elemento histórico ha de

${ }^{3} \mathrm{Me}$ atraen poco, personalmente, las polémicas estrictamente nominalistas, que desvían con frecuencia la atención de cuestiones más profundas y entitivas, y resultan habitualmente insidiosas y tremendamente aburridas. En todo caso, andalusí o hispanoárabe me parecen las denominaciones más apropiadas para referirse a la literatura que se escribió en al-Andalus, aunque yo, personalmente, prefiera la primera de ellas, por ser más directa y sintética. Otras, aunque sean sugerentes y eufónicas, conviene "aparcarlas", por inexactas, al menos parcialmente. Creo que se entiende perfectamente lo que quiero decir con "directas", que subrayo por ello. 
constituir, por consiguiente, uno de los componentes básicos, de las claves indispensables, en el estudio de la literatura hecho desde tales presupuestos. El método filologista ha sido especialmente $-\mathrm{y}$ abusivamente- aplicado al estudio de las tenidas por literaturas historicas y hasta por "literaturas muertas", expresión que, entre otras cosas, atenta contra la propia naturaleza y esencia de la literatura. Con suma frecuencia, la metodología filologista -de inevitable condición histórica implicada, repito- ha presentado finalmente los materiales literarios como en situación de pro indiviso, en forma bastante opaca y plana; por consiguiente, posiblemente aliteraria. La profesora Rubiera Mata, que recibe su formación esencial dentro de ese marco de estudio, pero en su modalidad especiffica de aplicación que hace el arabismo español universitario, que no coincide plena ni totalmente con tales presupuestos generales aludidos -lo que constituye ya de por si un dato significativo y esclarecedor-ve con lucidez, a mi juicio, las ventajas y los inconvenientes, las virtudes y los vicios, de esa metodología predominante, y con rigor y decisión se propone superarlos y depurarlos ${ }^{4}$. Rubiera ve con acierto que el método filológico-histórico es en raíz, y no en sus abundantes derivaciones cortas y desvirtuadas, una propuesta abierta y de propósito global, como consecuencia coherente, en buena parte, de su parcial ambigüedad y ajetreada trayectoria. $Y$, en consecuencia, busca y pone en práctica, cada vez con mayor y más evidente resolución, su manera personal y selectiva de aproximarse al texto literario y aproximarlo 5 .

${ }^{4}$ Por ejemplo: creo que queda muy claro que la incomparable aportación de García Gómez, patriarca indiscutible de estos estudios por varios motivos, desborda una estricta metodología filológica y es reflejo de una personalidad indiscutible, estructuralmente literaria, además, seguramente. Algo parecido -aunque en menor escala, atendiendo sobre todo a la gran diferencia cuantitativa existente entre las dos- cabria decir de la de Elías Terés, el "maestro de huella luminosa".

${ }^{5}$ Me parece que prueba bastante clara de lo que vengo diciendo, aunque no suficientemente explícita, por supuesto, es el prólogo que escribió don Emilio García Gómez a uno de los más importantes libros de la profesora Rubiera: Ibn $a l$-Ŷayăb, el otro poeta de la Alhambra (Granada, 1982), al elogiar dos aspectos de su obra: "el del estudio de la poesía arabigoandaluza y el de hacer taladros cada vez más útiles y nuevos en el campo de la historia nazari" (p. 7 ). 
La poesia ha constituido seguramente el objeto principal de atención en la obra de Rubiera Mata: la poesía árabe medieval, se entiende, y muy particularmente la poesía andalusí. Esta preferencia no tiene nada de extraño ni incoherente, es perfectamente explicable desde varios puntos, y responde ejemplarmente a ese común denominador e hilo conductor de su obra que se propone consciente y lúcidamente la renovación de una tradición. Sólo una visión raquítica y enormemente sesgada de la literatura árabe puede hacer pensar que la literatura árabe medieval es, estricta o eminentemente, una "literatura poética", olvidando o minimizando la difusión y el valor, sobresalientes también en muchísimas ocasiones, de la prosa, con formas, estilos, géneros y modos no menos originales, auténticos y representativos. Pero sí es cierto que la poesía ha gozado de un aprecio y devoción especiales, de una especie de idolatría, originada en parte, seguramente, en la naturaleza misma de la lengua árabe -metafórica como pocas, desde su propia materia fónica y estructura morfosemántica- y en la propia creencia de sus hablantes, que consideran tópica e impertubablemente a la poesía como su virtud (fadila) nacional o colectiva ${ }^{6}$. Añádase a todo ello, asimismo, el interés también absolutamente preferencial que los grandes maestros del arabismo español, del "andalusismo", han tenido por el estudio y el conocimiento de la producción poética hispanoárabe, y parecerá explicable y congruente, como decía, la postura de nuestra colega.

Este rasgo de continuidad no tiene nada que ver, sin embargo, con el continuismo. Los caminos y medios de ampliación y renovación, por el contrario, van a ser variados y de diverso rango en la obra de Rubiera Mata. Los más fácilmente observables y en definitiva los de menos importancia son los estrictamente cronológicos: ejemplo adecuado de ellos es la notable atención que la investigadora prestará a la poesía de época nazari, dentro del panorama de "taladros" cada vez

${ }^{6}$ En este sentido, las conocidas y antiguas definiciones de preclaros autores medievales, como Ibn Qutayba o al-Ȳạiz, encuentran su correspondiente y actualizado parangón en plena época contemporánea, en otros como Nizār Qabbānī, 'Abd al-Wahhāb al-Bayâtĩ o Adonis. Recientemente me ha interesado ponerlo brevemente de manifiesto en el prólogo que he escrito a la antología Tiempo de poesia árabe, $\mathrm{n}^{\circ}$ 33-34 de la revista Arrecife, Murcia, 1994. 
más útiles y nuevos a los que se refiere García Gómez, supongo que omitiendo la connotación ruidosa y dolorosa del término. Se ensayan y practican otros de mejor alcurnia y mayor alcance, practicando una valoración propiamente estética o cultural de la manifestación literaria. La autora sigue con frecuencia y habilidad, en este ejercicio, la aplicación de una técnica asociativa, no absolutamente original, desde luego, pero sí escasamente practicada entre arabistas. Por lo que tiene de significativo, y asimismo de temprano en su obra, traigo a colación un fragmento del párrafo final de su escrito sobre la poesía cinegética árabe: "Hemos intentado en estas páginas dar una visión general de lo que constituye el género Tarad. Sólo nos falta encuadrarlo en las categorfas estéticas que nos son al uso para comprender este género, ajeno a nuestra preceptiva. En realidad, el único paralelo que podemos encontrar en nuestra cultura, es la pintura. Recordemos la riqueza y minuciosidad de las escenas cinegéticas que en todos los tiempos ha plasmado la pintura, incluso el arte rupestre. Apuntamos la teoría de que casi toda la temática creada por los muhdatún, encuentra su paralelismo en la pintura occidental"?

La búsqueda plausible de unos fundamentos y recursos estéticos genuinos de la literatura árabe constituye, sin duda, una constante vertebradora de la obra de la profesora Rubiera Mata, y es posible que esté convirtiéndose, finalmente, en una auténtica obsesión. Ese creciente interés por percibir y definir los principios estéticos, aparte de poner de manifiesto la primacía de lo sensorial y un pensamiento de ráz claramente idealista, resulta particularmente comprensible y justificado cuando voluntariamente se pretende estudiar una literatura que, como la árabe, ha sido frecuentemente considerada, por los arabistas occidentales, como material esencialmente documental o técnico, de apoyo histórico interpretativo; no como realización en sí, sino para algo; como texto útil, en definitiva, más que como texto gozoso. La profesora Rubiera Mata, en consecuencia, restituye a la manifestación literaria lo que en puridad es y le pertenece; plantea problemas que son más "de literatura" que de simple "escritura", y sitúa por consiguiente

${ }^{7}$ Artículo incluido en el volumen de homenaje a F. M. Pareja, Orientalia Hispanica, edición a cargo de J. M. Barral, Leiden, I, 1974, pp. 566-573. 
a la manifestación literaria en una categoría superior y general: no ya la del hecho literario estrictamente, sino la del hecho creativo. Tampoco faltaban actitudes de esta condición en el arabismo europeo tradicional y no sólo en el español -el recuerdo a este respecto del italiano Francesco Gabrieli parece particularmente pertinente y justo- pero la investigadora se acredita desde luego como uno de sus puntales nuevos más sólidos y eficaces. Basta comparar el volumen de Literatura hispanoarabe (Madrid, 1992) de Rubiera Mata -su obra más importante y granada en el terreno de estudio que aquí nos ocupa- con los conocidos manuales de Ángel González Palencia y Juan Vernet ${ }^{8}$, para comprobar fehacientemente el largo camino recorrido y las profundas diferencias existentes entre dos maneras de entender, sentir y estudiar la literatura; también, de darla a conocer. Y esas netas y profundas diferencias no se explican tan sólo como consecuencia del avance investigador: aplicar solamente este argumento sería desnaturalizar la cuestión objeto de debate y transgredir los términos objetivos de éste.

Es natural que una concepción de esta naturaleza se complazca en destacar la presencia y actuación en el texto literario de otros ingredientes o elementos que pueden asumir con facilidad una función eminentemente estética, sensorial. Tal es el caso, por ejemplo, de la vista, la voz, el of́do y el color. Nuestra autora persigue su mención y su rastro en la literatura árabe -no sólo en la poesía, sino también en la prosa, aunque en la primera se produzcan seguramente de modo más descollante y con mayor brillo- con tino y satisfacción. Lo visual, por consiguiente, lo oral, lo auditivo, lo cromático, se van constituyendo como una trama o galaxia estética dotada de una doble realidad y dimensión trenzada: la material y la simbólica. Nos parece congruente, en consecuencia, que algunas de las páginas más logradas en la ya abundante obra de la autora, como resultado feliz y correcto de estos principios, se encuentren en su espléndido ensayo sobre la arquitectura en la literatura árabe. Como muy bien se observa en la traducción italiana de este libro, es producto de "l'univocita della sua ottica

${ }^{8}$ Respectivamente, Historia de la literatura arábigo-española, $2^{\mathrm{a}}$ ed., Barcelona, 1945, y Literatura árabe, Barcelona, 1966. 
letteraria, che peraltro appare giustificata"9. La visión de la profesora Rubiera es claramente integradora de los muy variados elementos -cada uno, gozando y ejerciendo su entidad particular- que posiblemente aparecen dispersos formal o estratégicamente, pero no en la trama subyacente estructural.

El estilo expositivo de la autora merece también algún comentario, pues aparece y se concreta, a mi juicio, como aplicación y resultado armónico de estos principios. En el párrafo que seguidamente transcribo se refleja con ejemplar nitidez, seguramente, y también las dotes que posee sin duda la investigadora para expresarse de manera próxima a la narrativa cinematográfica: "Fuera de los ambientes públicos y lúdicos, donde la literatura árabe rinde tributo al mundo mediterráneo al que pertenece, donde la palabra, hecha voz, es la reina, los literatos árabes escribieron sus libros o sus poemas rodeados de papeles, libros, apuntes, fichas, que leían a la luz de hachones, de candiles de aceite, de candelabros de oro, según su clase social. Durante muchas horas, días, años, escribieron con sus afilados cálamos en páginas blancas, en las que la escritura árabe se dibujaba con tinta negra o roja. La indolencia y la sensualidad desenfrenada oriental sólo forman parte de nuestra propia imaginación. La literatura árabe medieval es obra de "clérigos", en el sentido medieval de letrados, sin notas de orden sacerdotal" 10 .

No es encargo ni propósito de estas páginas estudiar el concepto de al-Andalus que tiene la profesora Rubiera Mata, ya que correspondería más bien a las exposiciones de carácter netamente histórico. No obstante, parece oportuno hacer alguna breve referencia al respecto, entre otras razones, porque el análisis que ella efectúa de los materiales literarios lo propicia y hasta, seguramente, exige. Diré asi, en resumen, que nuestra autora lo ve como sujeto extraordinariamente dinámico y participativo, situado con naturalidad y por derecho propio en el ámbito de interacciones inherente a la relación entre el mundo oriental y el occidental, por emplear una terminologia ya acuñada y en parte

- María Jesús Rubiera y Mata, L'immaginario e l'architettura nella letteratura araba medievale, a cura di Ennio Concina, Genova, 1990, p. IX.

${ }^{10}$ Literatura hispanoárabe, Madrid, 1992, pp. 46-47. 
convencional; es decir, como ente natural y plenamente mediterráneo. Reflexionando un poco habría que admitir que la idea es obvia y tiene en definitiva poco de sorprendente. Pero no deja de resultar también original y necesario el traerla nuevamente a colación y memoria, cuando una y otra vez se repite torpemente tanta opinión contraria 0 , sencillamente, se omite esa transparente realidad, indiscutible.

La buena formación de la investigadora en temática medieval genérica, es decir, no circunscrita solamente al mundo árabe islámico, aunque éste constituya su objeto principal de reflexión y tarea académicas y profesionales, la ayuda eficazmente en tal empeño. El variado material literario que conoce le permite establecer indagaciones y análisis que, a mi entender, superan con creces los consabidos y tradicionales planteamientos en términos de influencias -ya bastante desfasados y cortos, sinceramente- y plantear el debate, adelantar hipótesis y sugerencias, propuestas de explicación, vinculadas al menos parcialmente al bastante más fecundo y actual concepto de interculturalidad. Esto es algo particularmente presente en los estudios dedicados a las formas de poesía tradicional y poesía estrófica -jarchas, zéjeles, moaxajas- y su coexistencia con formas "occidentales" análogas y familiares. La buena documentación de primera mano, la capacidad asociativa -insisto en ello- de la investigadora, su esponjosa sensibilidad, le permiten ir perfilando un fascinante universo lírico trabado y en movimiento. Es de esperar que, siguiendo por ese camino, sus aportaciones futuras resulten aún más interesantes e innovadoras. La profesora Rubiera Mata posee lo fundamental para conseguirlo, aparte su sólida preparación cientifica puesta de manifiesto suficientemente: decisión, intuición y prudencia.

Por las mismas razones mencionadas inmediatamente antes, desistimos también de tratar algunos aspectos de la obra de nuestra apreciada colega que abordan contenidos ideológicos o, al menos, los suscitan o insinúan. Aunque la cuestión es atrayente como pocas y particularmente apasionante; hasta de conveniente planteamiento en el momento y lugar oportunos. Me limitaré también, por consiguiente, a hacer alguna rápida alusión al respecto. Tienen ahí cabida, por ejemplo, las numerosas observaciones, hipótesis, ideas y juicios que proporciona sobre la posible identidad cultural andalusí, lo que puede constiiuir uno de tantos alicientes parciales para la reconsideración de una cuestión 
subyacente y especialmente espinosa, quebradiza y pluriideologizada: el hipotético nacionalismo andalusf. En este vasto e intrincado terreno, las incitaciones resultan en realidad múltiples y arrebatadoras, repito, darían lugar a un encendido debate seguramente, que no tendría por qué dejar de ser esclarecedor. Traigamos a colación un simple ejemplo. Refiriéndose al colapso del califato omeya de Córdoba y el tránsito a los Taifas, la autora afirma: "Se produce, por tanto, la descentralización económica y cultural de al-Andalus, lo que, a la larga, será beneficioso, porque multiplicará las posibilidades de acceso a la riqueza, al poder y la cultura de todos los andalusies" ${ }^{11}$. La observación es penetrante, y ampliamente certera, seguramente. Pero cabría también preguntarse, y parece muy difícil sustraerse a hacer la pregunta: ¿podría afirmarse lo mismo desde un punto de vista político?, ¿tuvo también la descentralización efectos tan positivos y generales en esa otra parcela sustantiva de la existencia andalus??.

$$
\text { * * * }
$$

Quiero concluir con una afirmación que puede parecer un tanto marginal y secundaria, pero que se refiere a un aspecto de excepcional importancia en realidad, y con dos observaciones derivadas de mi experiencia e inquietud personales. La afirmación es ésta: la profesora Rubiera Mata es una inteligente engarzadora de textos y una excelente traductora. Para alguien que se propone aproximar y difundir la literatura, acicatar hacia ella, hacerla quizá prenda de encariñamiento, se trata de una condición sumamente positiva y absolutamente necesaria, más aún en el caso de un arabista. Estas cualidades están presentes en toda la obra de María Jesús Rubiera, se muestran ya en sus trabajos iniciales, pero seguramente alcanzan mayor peso y entidad en aquellos que la autora ha emprendido -al menos yo creo apreciarlo asi- con un cariño muy especial y sintiendo tal vez una especie de compromiso: caso de la antologfa del rey poeta de Sevilla o la dedicada a la lírica

${ }^{11}$ Literatura hispanoárabe, p. 21. La misma idea se expresa también en su Introducció a la literatura hispano-àrab (Alicante, 1989), pp. 33-34, aunque con algún interesante pequeño matiz añadido. 
femenina andalusi ${ }^{12}$. Ambos volúmenes cuentan además con sendos estudios introductorios que son acabado ejemplo de conocimiento a fondo y entrañable del tema, de ductilidad interpretativa.

Mi primera observación reitera una inquietud que vengo sintiendo y expresando desde hace ya algún tiempo. Insistiendo al máximo en la evidente "riqueza sensorial" de la literatura árabe -y en especial de la poesía- puede afianzarse también el viejo y erróneo estereotipo arabista de la extremada "pobreza intelectual" de la misma. Es cierto que los escritos de la profesora Rubiera Mata nada tienen que ver con este despropósito, pero quizá, torpe o indocumentadamente leídos, podrían equivocadamente servir de estímulo para seguir manteniendo interpretaciones tan desplazadas. La segunda reitera asimismo una aspiración y una necesidad, cada vez más evidente y urgente: la incorporación ponderada y consciente de la producción crítica literaria árabe contemporánea a nuestro caudal de conocimientos, junto a los arsenales bibliográficos ya conocidos y utilizados: los resultados serían muy positivos $^{13}$.

Me falta añadir algo para concluir esta apresurada aproximación a una parte especialmente sustanciosa, innovadora y original de la obra escrita de la profesora María Jesús Rubiera Mata: se nota que, cuando escribe, piensa también en el lector. No se trata de ningún mérito menor, precisamente.

${ }^{12}$ Al-Mu'tamid ibn 'Abbad. Poestas (Madrid, 1987) y Poesta femenina hispanoárabe (Madrid, 1990).

${ }^{13}$ Mencionaré simplemente algunos nombres de autores representativos dentro del variadísimo panorama de la crítica literaria académica árabe contemporánea, de distintas formaciones, tendencias y períodos, y renunciando a referirme a otros más conocidos y aceptados en los círculos arabistas. Por ejemplo: ${ }^{\mathrm{C}} \mathrm{Abd}$ al-Karīm al-Yāfĩ, Šawqī Dayf, Adonis, Kamāl Abūi-Dīb... Una sola cita concreta referente a la literatura andalusí: el importante libro de Sulaymān al- ${ }^{c}$ Atțăr, $a l-$ Jayăl wa-l-si ' $r$ fi-tasawwuf al-Andalus ("Imaginación y poesía en la mística de alAndalus"), El Cairo, 1981. Unas relaciones bibliográficas medianamente completas serían impropias de esta contribución. 